\title{
Theoretical prediction and experimental verification of light-load instability in a 11-kW open-loop induction motor drive
}

\author{
ANIRUDH GUHA $^{1, * \mathbb{D}}$, ABHISHEK CHETTY $^{2}, \mathrm{C} \mathrm{KUMARESAN}^{2}$, G NARAYANAN $^{1}$ and \\ R KRISHNAMOORTHY ${ }^{2}$ \\ ${ }^{1}$ Department of Electrical Engineering, Indian Institute of Science, Bangalore 560012, India \\ ${ }^{2}$ L\&T Technology Serivces, Bangalore 560045, India \\ e-mail: aguha@ee.iisc.ernet.in; anuguha87@gmail.com
}

MS received 14 March 2016; accepted 22 November 2016

\begin{abstract}
This paper presents the small-signal stability analysis of an 11-kW open-loop inverter-fed induction motor drive, including the effect of inverter dead-time. The analysis is carried out using an improved smallsignal model of the drive that has been reported in literature recently, and is used to demonstrate small-signal instability in a higher-power-level motor. Through small-signal stability analysis, the region of oscillatory behaviour is identified on the voltage versus frequency plane ( $V-f$ plane), considering no-load. These predictions using the improved model are also compared against predictions of a standard model of an inverter-fed induction motor including dead-time effect. The oscillatory behaviour of the 11- $\mathrm{kW}$ motor drive is also studied through extensive time-domain numerical simulations and actual measurements over wide ranges of operating conditions. Both the simulation and experimental results confirm the validity of the predictions by the improved analytical model. Further, these results establish that the analysis is valid for both sine-triangle pulse-width modulation (PWM) and conventional space vector PWM.
\end{abstract}

Keywords. Dead-time; induction motor; voltage source inverter; small-signal model; stability.

\section{Introduction}

Induction machines are widely used in the industry for various applications such as fans and pumps. Energy efficiency considerations have led to variable-speed operation of fans and pumps rather than fixed-speed operation. Openloop volt-per-hertz $(V / f)$ control is a simple control scheme for such applications. VIf control of induction motors is also widely employed in the industry during the testing stage of inverters and induction motors. A schematic of an open-loop inverter-fed induction motor with a simple $V / f$ control is shown in figure 1.

A number of open-loop $V / f$ induction motor drives have been reported to exhibit oscillatory behaviour at low and medium speeds, and particularly under light-load conditions [1-10]. This light-load instability phenomenon is impacted by motor parameters such as stator and rotor resistances, leakage and magnetising reactances and inertia $[1,3,10]$. Increased stator resistance of the motor is an important factor, which results in this light-load instability [2-5]. Further, the inverter dead-time, which is introduced for safe commutation of switches in an inverter, is reported to result in or accentuate these sub-harmonic oscillations in the induction motor [4-9]. Recently, inverter dead-time was shown to result in significant sustained sub-harmonic oscillations in a 100-kW induction motor [7-9].

Considering the importance of $V / f$ drives in the industry, this paper attempts to study the prevalence of such oscillations in commercial motor drives. Specifically, a case study on an 11-kW industrial motor drive is reported in this paper. The study presented here is a collaborative effort between an industry and an academic institution. This study comprises small-signal stability analysis, time-domain numerical simulations and actual measurements on an $11-\mathrm{kW}$ motor drive. The main objective here is to predict the region of oscillatory behaviour, if any, of the $11-\mathrm{kW}$ induction motor.

The small-signal stability analysis of induction motor is carried out by linearising its dynamic model about an equilibrium point. The standard or classical approach to stability analysis is to linearise the standard dynamic model of the induction motor available in textbooks and in literature $[1,11]$. However, the stator resistance is taken as the sum of actual resistance $\left(r_{s}\right)$ and an additional resistance $R_{e q 0}$, considered to include the dead-time effect [5-7]. This dead-time equivalent resistance depends on the dead-time error voltage $[5,7,12,13]$ and stator current. An accurate

*For correspondence 


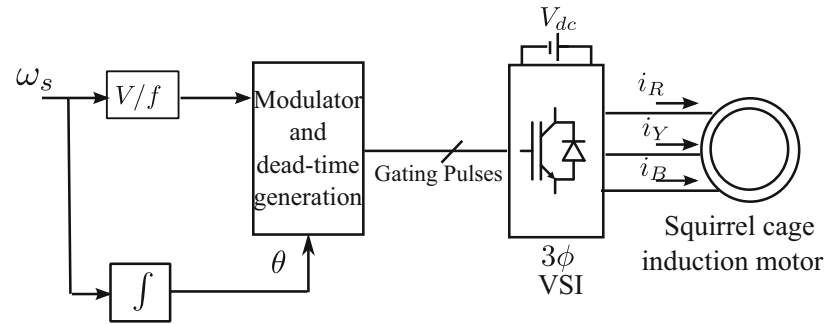

Figure 1. Schematic representation of an open-loop induction motor drive.

method to evaluate this equivalent resistance is presented in [14].

Recently, a more rigorous analysis of the dead-time effect on the inverter output has led to an improved smallsignal model for the inverter-fed induction motor [9]. The dead-time effect on the inverter output has been studied in the synchronous $d q$ reference frame $[15,16]$. This has led to a modified dynamic model of the inverter-fed induction motor [14]. Linearisation of this modified dynamic model has resulted in an improved small-signal model for stability analysis. The improved and standard small-signal models are reviewed in section 2 of this paper.

Both the improved and standard small-signal models are used to perform the stability studies on the $11-\mathrm{kW}$ induction motor drive, in section 3 . These models are used to predict the regions of oscillatory behaviour of the $11-\mathrm{kW}$ drive. Evaluation of the validity of the two models is another objective here. Extensive simulation results presented in section 4 validate the small-signal analysis and the region of oscillatory behaviour as predicted by the improved small-signal model. An extensive experimental study on the $11-\mathrm{kW}$ induction motor, presented in section 5, confirms the oscillatory behaviour in the drive as predicted by the improved model. A preliminary version of this paper was presented in [17]. This full paper presents additional analytical, simulation and experimental results for different ratios of dead-time to switching cycle time so that more general conclusions could be drawn.

\section{Review of small-signal model of an open-loop induction motor drive}

The dynamic model of the induction motor drive [14] and the linearised small-signal models of the drive $[5,8,9]$ are reviewed in the following subsections.

\subsection{Modified induction motor dynamic equations}

Inverter dead-time is known to cause an error voltage pulse in each switching cycle, the polarity of which depends on the load current polarity $[12,13]$. The switching-cycle average of this error voltage is seen to be a square wave over a fundamental cycle; the polarity of this square wave depends on the sign or polarity of the load current $[12,13]$. The dead-time error voltages are analysed in the synchronous $d q$ reference frame in $[15,16]$. In [15], the fundamental components of the dead-time error voltages in the $R Y B$ reference frame are considered, and are transformed to the $d q$ reference frame, resulting in error voltage drops that depend on the $q$-axis and $d$-axis inverter output currents. These error voltage drops are incorporated into the stator dynamic equations, which can be rewritten as follows [14]:

$$
\begin{aligned}
v_{q s, i d}= & \left(r_{s}+\frac{\left|\vec{V}_{s, e r r . f}\right|}{\sqrt{i_{q s}^{2}+i_{d s}^{2}}}+L_{s} \frac{d}{d t}\right) i_{q s}+\omega_{s} L_{s} i_{d s} \\
& +L_{m} \frac{d i_{q r}^{\prime}}{d t}+\omega_{s} L_{m} i_{d r}^{\prime} \\
v_{d s, i d}= & -\omega_{s} L_{s} i_{q s}+\left(r_{s}+\frac{\left|\vec{V}_{s, e r r . f}\right|}{\sqrt{i_{q s}^{2}+i_{d s}^{2}}}+L_{s} \frac{d}{d t}\right) i_{d s} \\
& -\omega_{s} L_{m} i_{q r}^{\prime}+L_{m} \frac{d i_{d r}^{\prime}}{d t}
\end{aligned}
$$

Here, $i_{q s}$ and $i_{d s}$ are the $q$-axis and $d$-axis stator, respectively. For any continuous pulse-width modulation (PWM) scheme such as sine-triangle PWM (SVPM) or conventional space vector PWM (CSVPM), the magnitude of the dead-time error voltage vector is given by (3)

$$
\left|\vec{V}_{s, e r r, f}\right|=\frac{4}{\pi} V_{d c} t_{d} f_{s w}
$$

where $V_{d c}$ is the dc bus voltage, $t_{d}$ is the inverter dead-time and $f_{s w}$ is the switching frequency $[14,16]$. Further, $v_{q s, i d}$ is the ideal $q$-axis stator voltage applied by an ideal inverter without dead-time. Since the ideal voltage vector is aligned along the $q$-axis, its component $v_{d s, i d}$ along the $d$-axis is zero. The rotor voltage equations and the mechanical dynamic equations are the standard equations as given in $[8,9,11]$. These equations together constitute the modified dynamic model of an induction motor, including the deadtime effect [14].

\subsection{Small-signal model}

The improved small-signal model is derived by linearising the modified dynamic equations of the induction motor [14] about a steady operating point. The determination of the steady-state solution/operating point including the effect of dead-time is presented in [14].

The linearised small-signal model of an inverter-fed induction motor with significant dead-time can be expressed in the standard form [9] as follows: 


$$
\Delta \dot{\mathbf{x}}=\mathbf{A} \Delta \mathbf{x}+\mathbf{B} \Delta \mathbf{u}
$$

where

$$
\mathbf{A}=\left[\begin{array}{cc}
-\mathbf{L}^{-1} \mathbf{R} & -\mathbf{L}^{-1} \lambda_{10} \\
\left(\frac{3}{2 J}\right)\left(\frac{\text { poles }}{2}\right)^{2} \lambda_{\mathbf{2 0}}^{\mathbf{T}} & -\frac{B}{J}
\end{array}\right]
$$

The various constituent matrices are given in [9], and are reproduced in the appendix of this paper. The specific constituent matrix, whose elements are impacted by the inverter dead-time, is the matrix $\mathbf{R}$, which may be expressed as follows:

$$
\mathbf{R}=\left[\begin{array}{ll}
\mathbf{R}_{s s} & \mathbf{R}_{s r} \\
\mathbf{R}_{r s} & \mathbf{R}_{r r}
\end{array}\right]
$$

More specifically, it is the sub-matrix $\mathbf{R}_{s s}$ in (6) that is directly influenced by dead-time. This sub-matrix $\mathbf{R}_{s s}$ is
Table 1. Induction motor parameters (star equivalent).

$r_{s}$ (stator resistance)

$r_{r}^{\prime}$ (rotor resistance referred to stator side)

$0.359 \Omega$

$L_{s}$ (stator inductance)

$82.46 \mathrm{mH}$

$L_{r}^{\prime}$ (rotor inductance referred to stator side)

$84.94 \mathrm{mH}$

$L_{m}$ (mutual inductance)

$79.82 \mathrm{mH}$

$J$ (inertia)

$0.0685 \mathrm{kgm}^{2}$

described differently in the standard [5, 6] and improved small-signal models [9].

2.2a Standard small-signal model: In steady state, the effect of dead-time is seen as an equivalent resistance $\left(R_{e q 0}\right)$ that adds to the stator resistance of the motor [5-7]. In the standard model [5], the dead-time equivalent resistance $\left(R_{e q 0}\right)$ is just added to the stator resistance $r_{s}$. The $\mathbf{R}_{s s}$ submatrix used in the standard model is given below as follows:
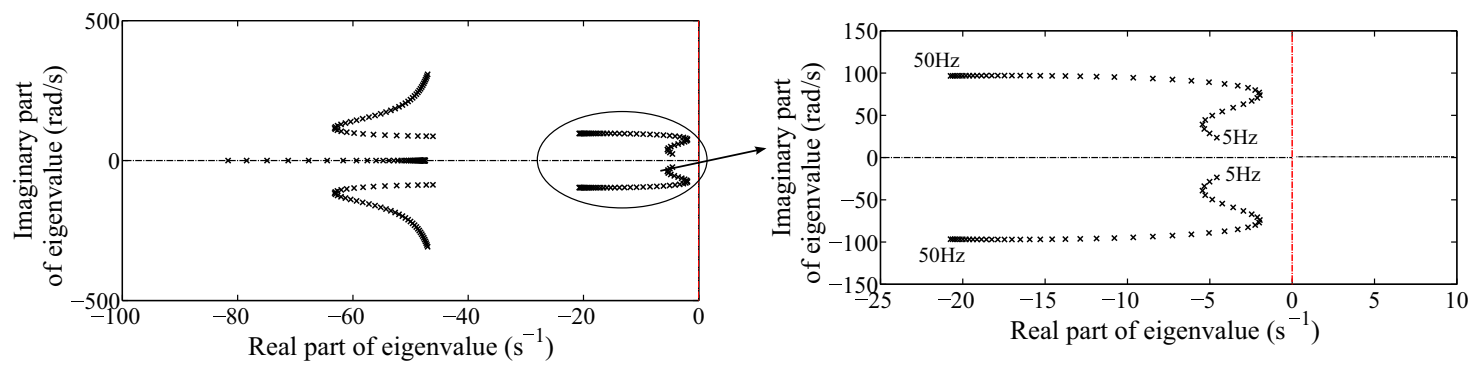

(a)
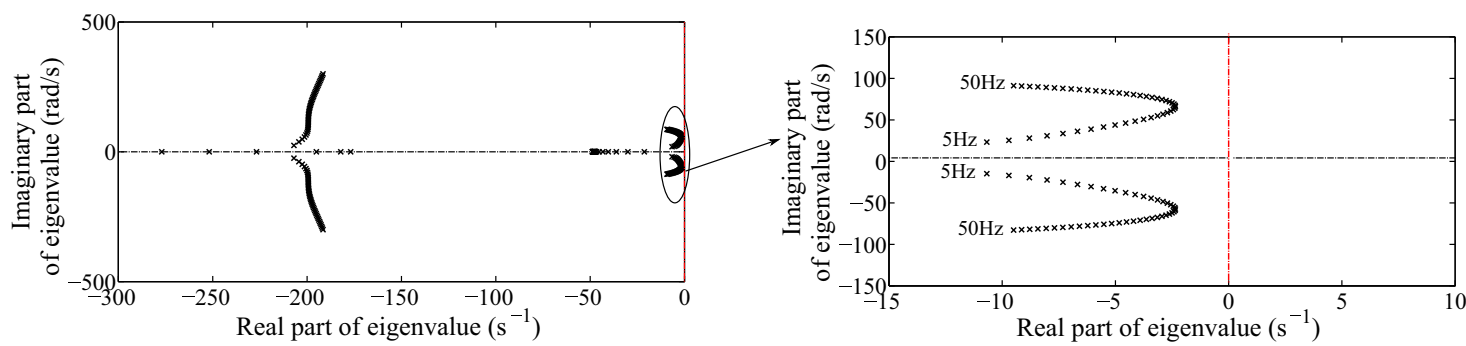

(b)

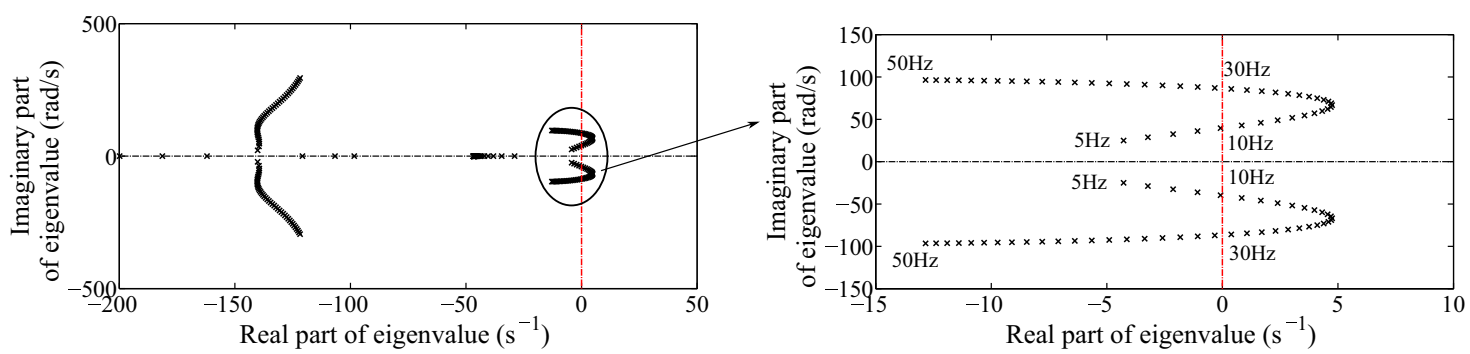

(c)

Figure 2. Loci of the eigenvalues of an $11-\mathrm{kW}$ inverter-fed induction motor under no-load for a speed range of $5-50 \mathrm{~Hz}$ considering (a) no-dead-time effect, (b) the standard model with $t_{d}=3 \mu \mathrm{s}$ and $f_{s w}=5 \mathrm{kHz}$ (i.e. $t_{d} f_{s w}=0.015$ ) and (c) improved model with $t_{d}=3 \mu \mathrm{s}$ and $f_{s w}=5 \mathrm{kHz}$ (i.e. $t_{d} f_{s w}=0.015$ ). A dc bus voltage of $V_{d c}=600 \mathrm{~V}$ and a $V / f$ ratio of 0.89 pu are considered in the analysis. 


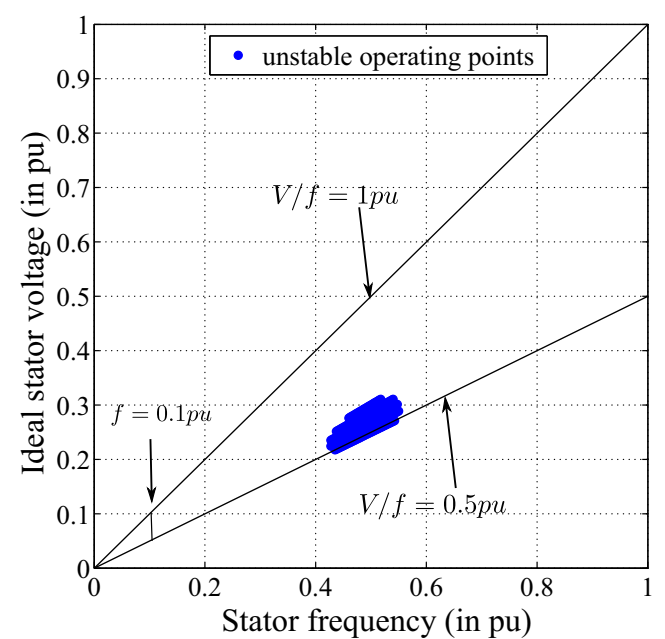

Figure 3. Stable and unstable equilibrium points in the $V-f$ plane for an $11-\mathrm{kW}$ induction motor drive under no load, as predicted by the standard small-signal model [5], considering $V_{d c}=600 \mathrm{~V}$ and $t_{d} f_{s w}=0.024$.

$$
\mathbf{R}_{s s, s t d}=\left[\begin{array}{cc}
r_{s}+R_{e q 0} & \omega_{s 0} L_{s} \\
-\omega_{s 0} L_{s} & r_{s}+R_{e q 0}
\end{array}\right] .
$$

2.2b Improved small-signal model: As mentioned earlier, the improved small-signal model [9] is obtained by linearising the modified dynamic equations of the induction motor, which includes Eqs. (1)-(3). The sub-matrix $\mathbf{R}_{\mathbf{s s}}$ in the improved small-signal model, thus derived, turns out to be as follows:

$$
\mathbf{R}_{s s, i m p r}=\left[\begin{array}{cc}
r_{s}+R_{q, e q 0} & \omega_{s 0} L_{s}-X_{q d, e q 0} \\
-\omega_{s 0} L_{s}-X_{q d, e q 0} & r_{s}+R_{d, e q 0}
\end{array}\right]
$$

where

$$
\begin{gathered}
R_{q, e q 0}=R_{e q 0}\left(\frac{i_{d s 0}^{2}}{i_{q s 0}^{2}+i_{d s 0}^{2}}\right) ; R_{d, e q 0}=R_{e q 0}\left(\frac{i_{q s 0}^{2}}{i_{q s 0}^{2}+i_{d s 0}^{2}}\right) \\
X_{q d, e q 0}=R_{e q 0}\left(\frac{i_{q s 0} i_{d s 0}}{i_{q s 0}^{2}+i_{d s 0}^{2}}\right) ; R_{e q 0}=\frac{\left|\vec{V}_{s, e r r, f}\right|}{\sqrt{i_{q s 0}^{2}+i_{d s 0}^{2}}} .
\end{gathered}
$$

The improved small-signal model suggests that the deadtime effect is more than just an equivalent resistance in series with the stator resistance, unlike what is portrayed by the standard model. The improved model shows that deadtime effect contributes to different values of $q$-axis and $d$ axis resistances, and also cross-coupling reactance terms between the two axes. These equivalent resistances and reactances appear from the linearisation of the dead-time error voltage terms in the stator dynamic equations. An evaluation of the validity of the two models in predicting the oscillatory behaviour of the $11-\mathrm{kW}$ drive is an objective of the paper.

\section{Small-signal stability analysis of an $11-\mathrm{kW}$ motor drive}

Stability analysis of an 11-kW, 21-A, 415-V, 4-pole, 50 $\mathrm{Hz}$, three-phase induction motor (parameters in table 1) is carried out over a wide operating range. An operating point of the motor drive is defined by the fundamental or modulating frequency, applied voltage and load torque. Since oscillatory behaviour of the motor drives is known to be largely under light loads $[4,5,9]$, the analysis is limited to no-load conditions here. The range of fundamental frequency considered is from $5 \mathrm{~Hz}$ to $50 \mathrm{~Hz}$. The corresponding range of fundamental voltage depends on the $V / f$ ratio chosen. While rated $V / f$ ratio (i.e. $V / f=1 \mathrm{pu}$ ) is usually employed, the motor drive is also operated in under-flux conditions at light loads. Hence $V / f$ ratio as low as $0.5 \mathrm{pu}$ is considered for the analysis. For a given applied frequency and voltage, the steady-state solution of the drive including the effect of dead-time is determined first [14]. The steady values of state variables, along with the motor parameters and dead-time equivalent resistance, yield the elements of the small-signal stability matrix A. The eigenvalues of matrix $\mathbf{A}$ are then evaluated to determine the small-signal stability of the drive at the given operating point.

When the dead-time effect is ignored (i.e. ideal case), the eigenvalues of matrix $\mathbf{A}$ vary with fundamental frequency as shown in figure 2 a for a $V / f$ ratio of 0.89 pu. A dc bus voltage of $600 \mathrm{~V}$, a typical switching frequency $f_{s w}$ of $5 \mathrm{kHz}$ and a dead-time of $3 \mu \mathrm{s}$ are then considered. When the dead-time effect is incorporated as suggested by the standard small-signal model [5], the eigenvalues of matrix $\mathbf{A}$ change with the fundamental frequency as shown in figure $2 \mathrm{~b}$, for the same $V / f$ ratio of $0.89 \mathrm{pu}$. While the root loci obtained with standard model (figure $2 b$ ) are significantly different from those with the ideal case (figure 2a), all eigenvalues are to the left of the $j \omega$-axis in both cases for all frequencies. However, when dead-time effect is incorporated as proposed by the improved small-signal model [9], a complex conjugate pair of root loci traverses to the right of the $j \omega$-axis for fundamental frequencies between 10 and 30 Hz. Thus, the improved small-signal model suggests oscillatory behaviour of the motor drive in the speed range between 10 and $30 \mathrm{~Hz}$, at a $V / f$ ratio of $0.89 \mathrm{pu}$. This will be verified through simulations and experiments in the later sections of the paper.

This analysis is repeated for different values of $V / f$ ratios between 0.5 and $1 \mathrm{pu}$. Also, different values of $f_{s w}$ and/or $t_{d}$ that are of interest need to be considered. As seen from Eq. (3), the magnitude of dead-time error voltage depends on the product $t_{d} f_{s w}$, at any given $V_{d c}$. Hence, apart from the value $t_{d} f_{s w}=0.015$, one lower value of 0.006 and a higher value of 0.024 are considered.

The unstable operating points (corresponding to different $V / f$ ratios and fundamental frequencies) may be identified 
on the $V-f$ plane through the stability analysis discussed earlier. Considering the ideal case without dead-time, no unstable operating points are seen in the $V-f$ plane. Considering a standard model where dead-time is just an equivalent resistance, no unstable operating points are seen with $t_{d} f_{s w}=0.006$, and $t_{d} f_{s w}=0.015$. However, there is a small region of instability when $t_{d} f_{s w}=0.024$ as shown in figure 3 .

On the other hand, when the stability analysis is performed using the improved small-signal model, significant regions of instability are identified on the $V-f$ plane for $t_{d} f_{s w}=0.006, t_{d} f_{s w}=0.015$ and $t_{d} f_{s w}=0.024$ as shown in figure $4 \mathrm{a}, \mathrm{b}$, and $\mathrm{c}$, respectively. The region of oscillatory behaviour is found to expand as $t_{d} f_{s w}$ product increases. The boundaries of the regions of instability are shown for different values of $t_{d} f_{s w}$ in figure $4 \mathrm{~d}$.

The analytically predicted region of instability of the $11-\mathrm{kW}$ motor drive is verified through time-domain simulations in the following section.

\section{Simulation results}

The simulation model essentially consists of the standard dynamic equations of the induction motor in the synchronous $d q$-reference frame [11], whose inputs are fed

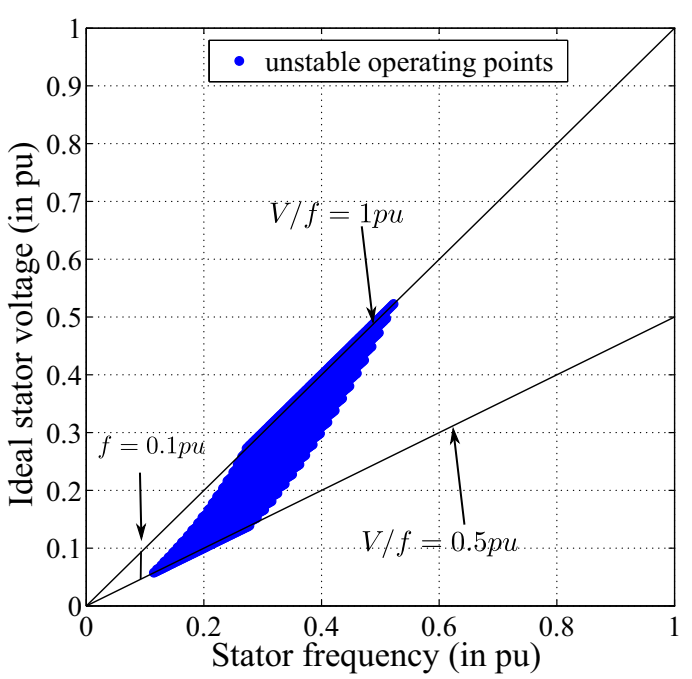

(a)

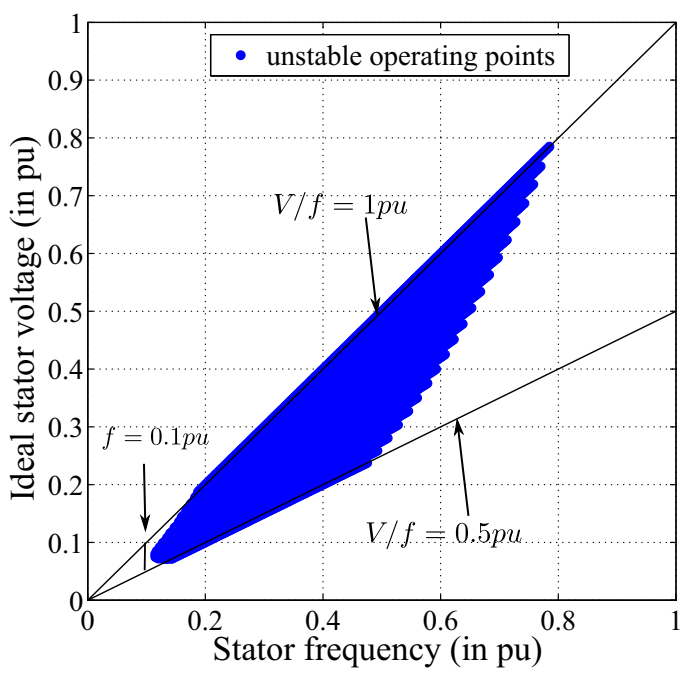

(c)

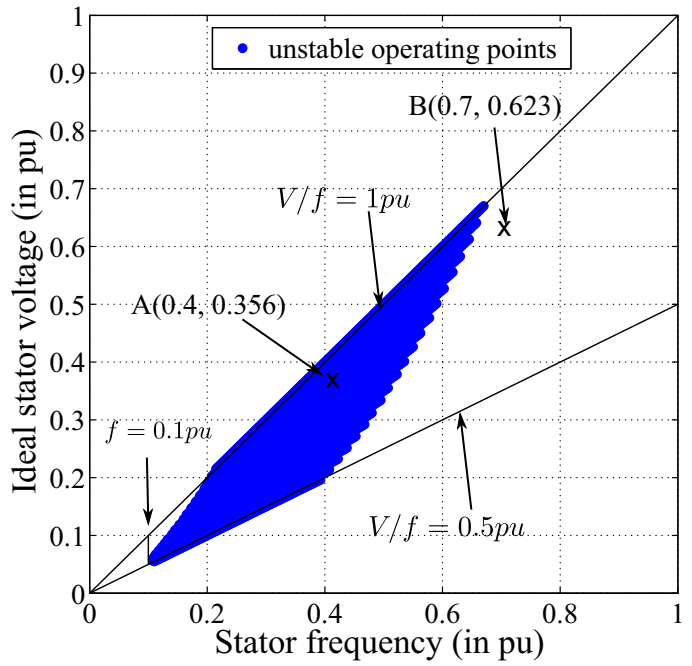

(b)

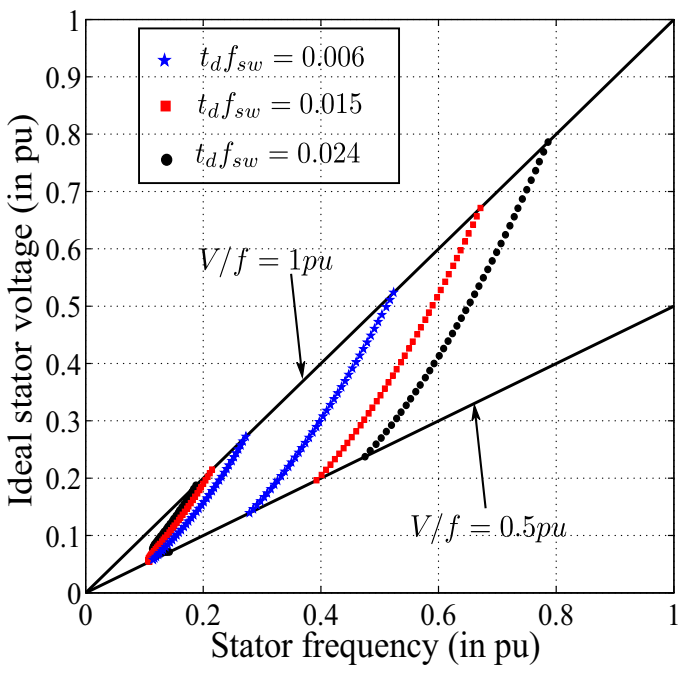

(d)

Figure 4. Stable and unstable equilibrium points in the $V-f$ plane for an $11-\mathrm{kW}$ induction motor drive under no load, as predicted by the improved small-signal model [9], considering $V_{d c}=600 \mathrm{~V}$ and (a) $t_{d} f_{s w}=0.006$, (b) $t_{d} f_{s w}=0.015$ and (c) $t_{d} f_{s w}=0.024$. (d) Variation of the region of instability with $t_{d} f_{s w}$ for the given dc bus voltage. The stability analysis is limited to frequencies between 0.1 and 1 pu, and for $V / f$ ratios between $0.5 \mathrm{pu}$ and $1 \mathrm{pu}$. The frequency base is $50 \mathrm{~Hz}$, and the line to line voltage base is $415 \mathrm{~V}$. 
from an inverter model including the dead-time effect. The ideal sinusoidal inverter output voltages are modified by adding the square-wave error voltages on account of inverter dead-time [5,7]. The resultant inverter output voltages are transformed to voltages in the synchronous $d q$ reference frame [16] and fed to the standard induction motor dynamic model.

For the simulations, the $11-\mathrm{kW}$ induction motor (parameters in table 1) and $t_{d} f_{s w}=0.015$ are considered initially. The simulated waveforms at the operating point A (in figure $4 \mathrm{~b}$ ), i.e. at fundamental frequency $f_{1}=20 \mathrm{~Hz}$, and $V / f=0.89 \mathrm{pu}$, are shown in figure 5 . Low-frequency oscillations of about $10 \mathrm{~Hz}$ are observed in the $q$-axis and $d$ axis currents in the steady state, indicating the operating point A to be unstable. These $q$-axis and $d$-axis currents are expected to be constant in the steady state for a stable operating point. These oscillations in the $q$-axis and $d$-axis currents reflect in the amplitude of the $R$-phase current shown in the same figure. Low-frequency $10 \mathrm{~Hz}$ oscillations are also seen in the motor torque and speed. It is observed that the torque developed is both positive and negative, indicating motoring and generating operation, respectively. Correspondingly, the rotor speed also accelerates and decelerates about the synchronous speed.

Simulations are repeated at various operating points in the $V-f$ plane (corresponding to different fundamental speeds and $V / f$ ratios) to identify the set of unstable operating points. The oscillatory region on the $V-f$ plane may be identified for different values of $t_{d} f_{s w}$. The regions of oscillatory behaviour for $t_{d} f_{s w}=0.006, t_{d} f_{s w}=0.015$ and $t_{d} f_{s w}=0.024$ obtained through simulations are shown in figure $6 \mathrm{a}, \mathrm{b}$ and $\mathrm{c}$, respectively. An unstable operating point is indicated by a shaded circle in the $V-f$ plane. These regions of oscillatory behaviour, determined using the simulation model, are in very good agreement with the corresponding regions predicted by the improved smallsignal model in figure $4 \mathrm{a}, \mathrm{b}$ and $\mathrm{c}$.

\section{Experimental results}

The experimental set-up consists of a three-phase, $415-\mathrm{V}$, 21-A, 11-kW, squirrel cage induction motor, fed from a two-level IGBT-based voltage source inverter, as mentioned before. The voltage source inverter is initially switched at a frequency of $5 \mathrm{kHz}$, and the inverter deadtime is $3 \mu \mathrm{s}$. The dc bus voltage is set to $600 \mathrm{~V}$ using a controlled voltage source. The $V / f$ control is implemented on a TMS320F28035-based controller, and the gating pulses generated are fed to the inverter switches through the gate-drive circuitry.

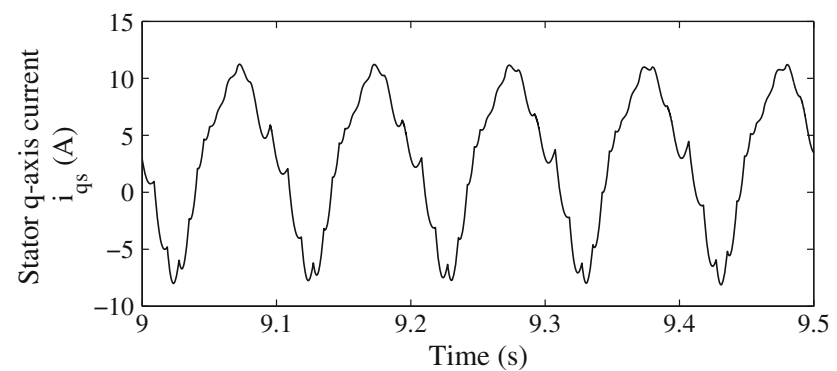

(a)

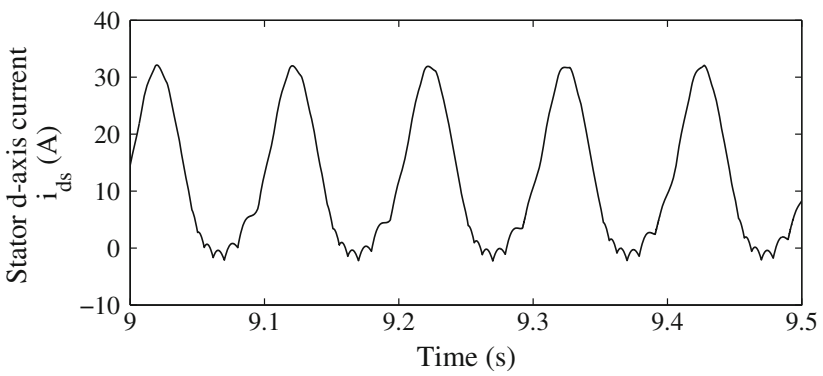

(b)

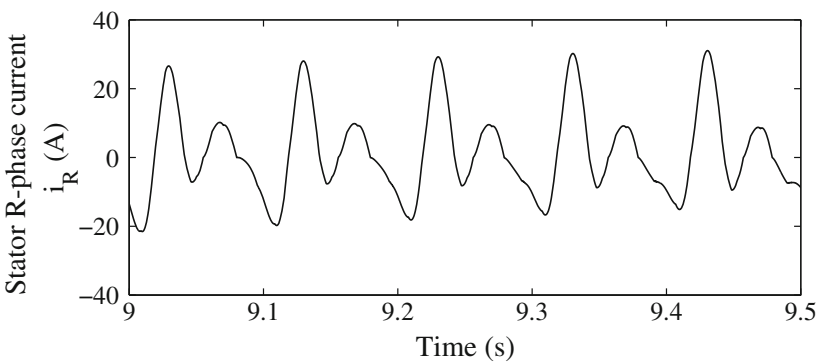

(c)

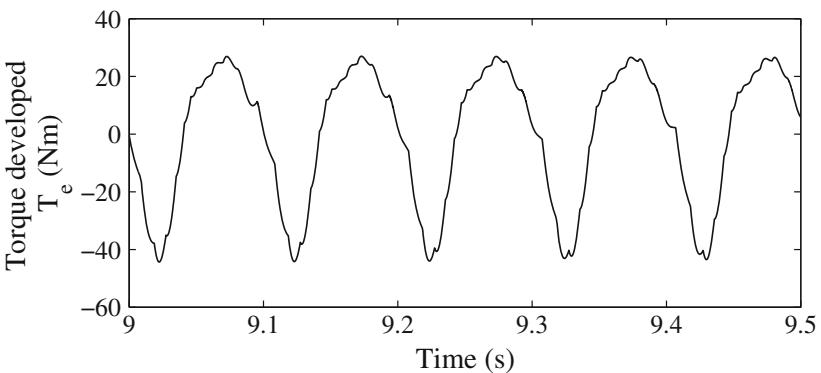

(d)

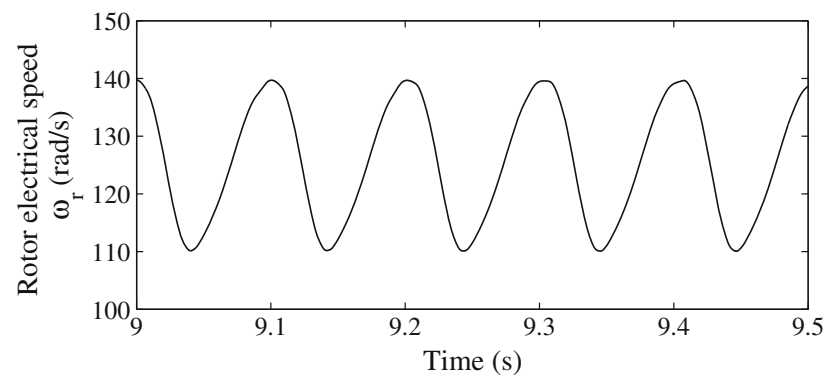

(e) 
4Figure 5. Sub-harmonic oscillations observed in the simulated (a) $q$-axis stator current, (b) $d$-axis current, (c) $R$-phase stator current, (d) torque developed, and (e) rotor electric speed at the unstable equilibrium point $\mathrm{A}$ (shown in figure $4 \mathrm{~b}$ ). A $t_{d} f_{s w}=0.015$ is considered.

\subsection{Sub-harmonic oscillations in the 11-kW drive}

At the operating point $\mathrm{A}$ indicated in figure 4(b) (i.e. at $f_{1}=0.4$ pu and $V / f=0.89 \mathrm{pu}$ ), the measured $R$-phase stator current (trace 1), $Y$-phase stator current (trace 2) and dc bus voltage (trace 3 ) are as shown in figure 7 . The measurements with SPWM scheme are shown in figure 7a, while those with CSVPWM are shown in figure 7b. Sub-harmonic oscillations are observed in the current waveforms in figure 7 , confirming the operating point $A$ to be unstable. The dc bus voltage is also found to be oscillatory with a peakpeak voltage of about $25 \mathrm{~V}$.

The measured stator currents and DC bus voltage at the operating point $\mathrm{B}$ in figure $4 \mathrm{~b}$, i.e at $f_{1}=0.7 \mathrm{pu}$ and $V / f=$ $0.89 \mathrm{pu}$, are shown in figure 8 . The waveforms in figure $8 \mathrm{a}$ and figure $8 \mathrm{~b}$ correspond to SPWM and CSVPWM schemes, respectively. No sub-harmonic oscillations are observed in the measured currents and DC bus voltage, indicating the operating point $\mathrm{B}$ to be stable.

\subsection{Region of oscillatory behaviour}

The oscillatory behaviour, if any, of the motor drive is examined experimentally at different $V / f$ ratios. $V / f$ ratios between 0.5 and $1 \mathrm{pu}$ in steps of $0.1 \mathrm{pu}$ are considered for the measurements. For each $V / f$ ratio, the drive is operated at speeds ranging between 5 and $50 \mathrm{~Hz}$ (say in steps of $1 \mathrm{~Hz}$ ) to identify the unstable operating points. Considering the SPWM scheme, the set of unstable operating points are identified experimentally, and are indicated on the $V-f$ plane in figure 9a. Similarly, the region of oscillatory behaviour with CSVPWM is shown in figure $9 \mathrm{~b}$. Thus, if a drive exhibits oscillatory behaviour with SPWM scheme, it should be expected to exhibit such oscillatory behaviour with CSVPWM scheme as well. Further, the region of oscillatory behaviour is almost the same for the two methods. This should also be expected in the light of the theoretical knowledge that the magnitude of the error voltage vector [see Eq. (3)] is equal for the two methods.

The experimentally determined region of oscillatory behaviour (figure 9a and b) match reasonably well with the simulated (figure 6b) and analytically predicted (figure 4b) regions.

Experiments are also performed at an increased switching frequency of $8 \mathrm{kHz}$ and for the same dead-time duration of $3 \mu$ s (i.e. $t_{d} f_{s w}=0.024$ ) and dc bus voltage of $600 \mathrm{~V}$. The regions of oscillatory behaviour at this switching frequency, considering SPWM and CSPWM are shown in figure $10 \mathrm{a}$ and $\mathrm{b}$ respectively.

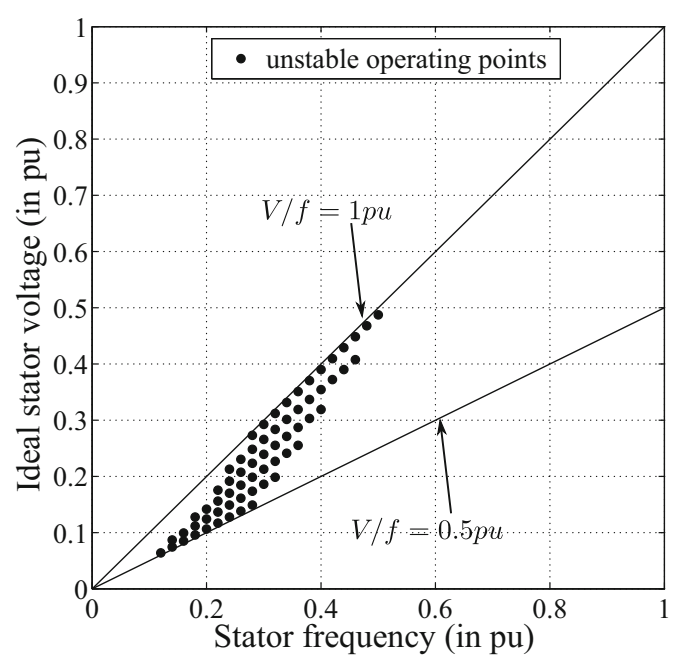

(a)

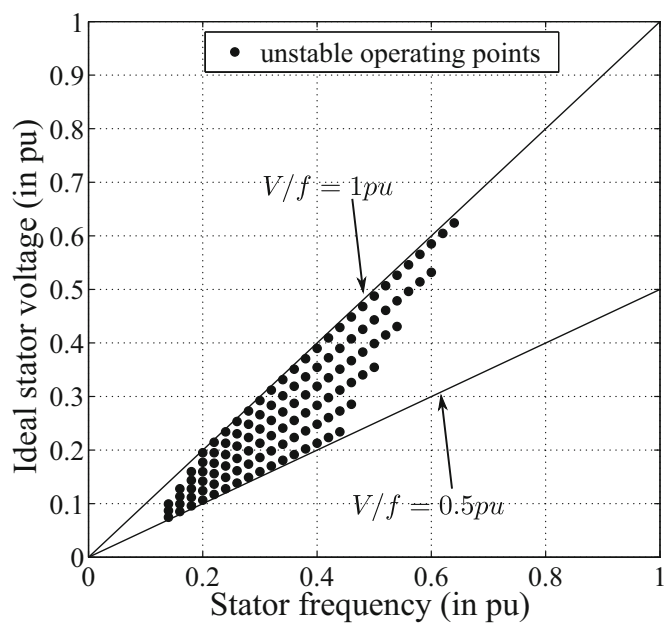

(b)

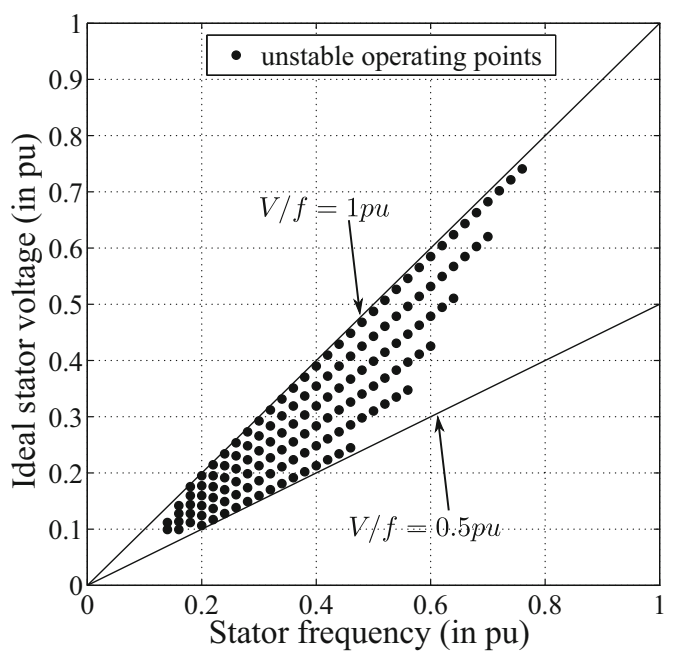

(c)

Figure 6. Stable and unstable equilibrium points in the $V-f$ plane for an 11-kW induction motor drive under no load, as observed from the time-domain simulation model, considering $V_{d c}=600 \mathrm{~V}$ and (a) $t_{d} f_{s w}=0.006$, (b) $t_{d} f_{s w}=0.015$ and (c) $t_{d} f_{s w}=0.024$. 


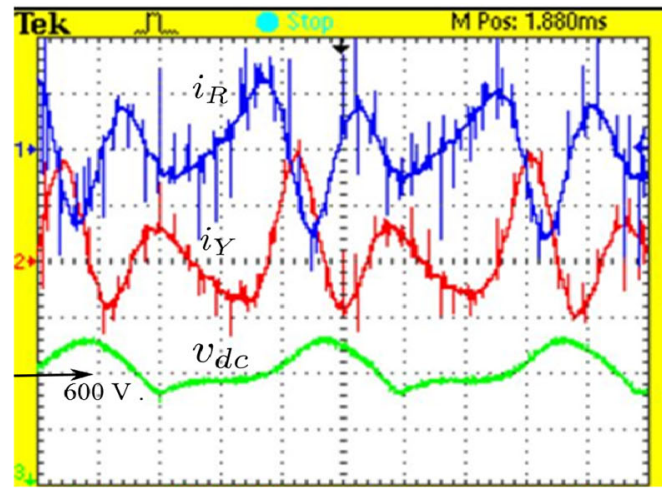

(a)

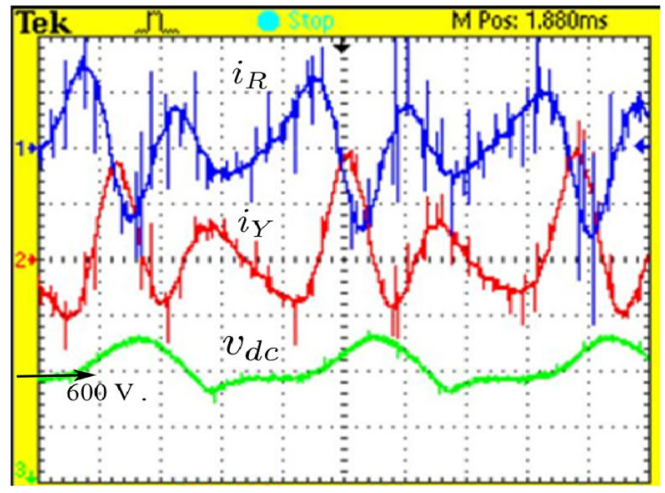

(b)

Figure 7. Measured stator currents and DC bus voltage at unstable operating point A (see figure 4b). (a) Sine-triangle PWM and (b) conventional space vector PWM. Trace 1: $R$-phase stator current (10 A/div), Trace 2: Y-phase stator current (10 A/div), and Trace 3: DC bus voltage ( $25 \mathrm{~V} / \mathrm{div})$. Time scale: $25 \mathrm{~ms} / \mathrm{div}$.

These results are in reasonable agreement with the simulated (see figure 6c) and analytically predicted (see figure $4 \mathrm{c})$ regions.

Minor deviations between the experimental and simulated results could be on account of a few factors such as device drops, device switching delays, variable switching transition slopes of the inverter output voltages and minimum on/off times, which are difficult to incorporate in simulation and analysis. Also, in the analysis and simulation, the dc voltage is assumed to be constant. However, in the experiments, the dc bus voltage is observed to oscillate at sub-harmonic frequencies. Modelling such dc-side dynamics would add to the model complexity. Despite ignoring such effects, the predictions of oscillatory behaviour by the improved small-signal model and simulation are in reasonable agreement with the experimental results.

\subsection{Mitigation of oscillatory behaviour using dead-time compensation}

These sub-harmonic oscillations could be mitigated to an extent by employing a simple dead-time compensation

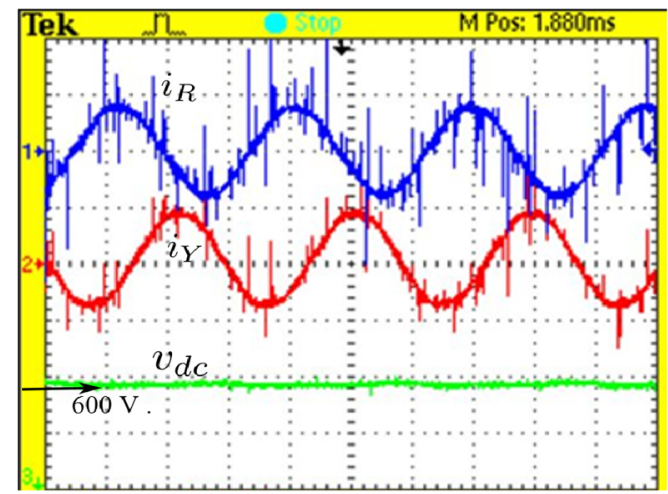

(a)

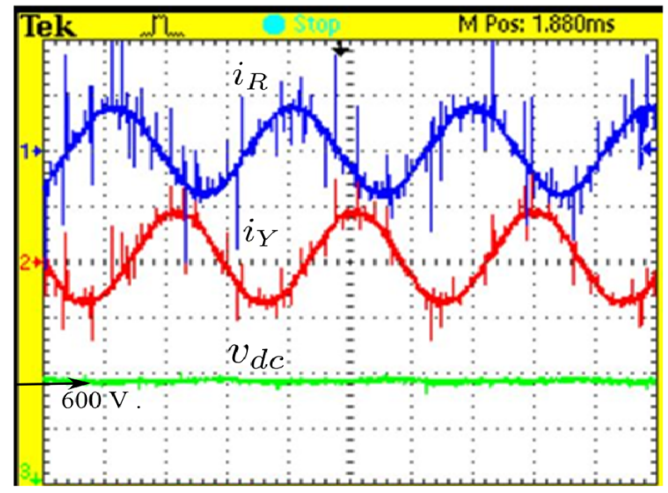

(b)

Figure 8. Measured stator currents and DC bus voltage at stable operating point B (see figure $4 b$ ). (a) Sine-triangle PWM and (b) conventional space vector PWM. Trace 1: $R$-phase stator current $(10 \mathrm{~A} / \mathrm{div})$, Trace 2: $Y$-phase stator current $(10 \mathrm{~A} / \mathrm{div})$, and Trace 3: DC bus voltage (25 V/div). Time scale: $10 \mathrm{~ms} /$ div.

scheme [7, 13]. A square-wave compensating signal, dependent on the current polarity, is added to the ideal sinusoidal modulating signal to compensate for the deadtime error voltage [7, 13]. The measured waveforms with dead-time compensation at the operating point $\mathrm{A}$ in figure $4 \mathrm{~b}$ (i.e. $f_{1}=20 \mathrm{~Hz}$ and $V / f=0.89 \mathrm{pu}$ ) are shown in figure 11. As opposed to the oscillatory waveforms before compensation as shown in figure $7 \mathrm{a}$, the current waveform after compensation in figure 11 does not show any subharmonic oscillations.

\section{Discussion}

The results in the previous sections establish the validity of the improved small-signal model in predicting light-load instability of the $11-\mathrm{kW}$ induction motor drive. This same model has also been shown recently to be more accurate than the standard small-signal model in predicting the region of sub-harmonic oscillations in a $100-\mathrm{kW}$ induction motor drive [9]. The two sets of results together establish the applicability of the improved small-signal model to motor drives of different power levels. 


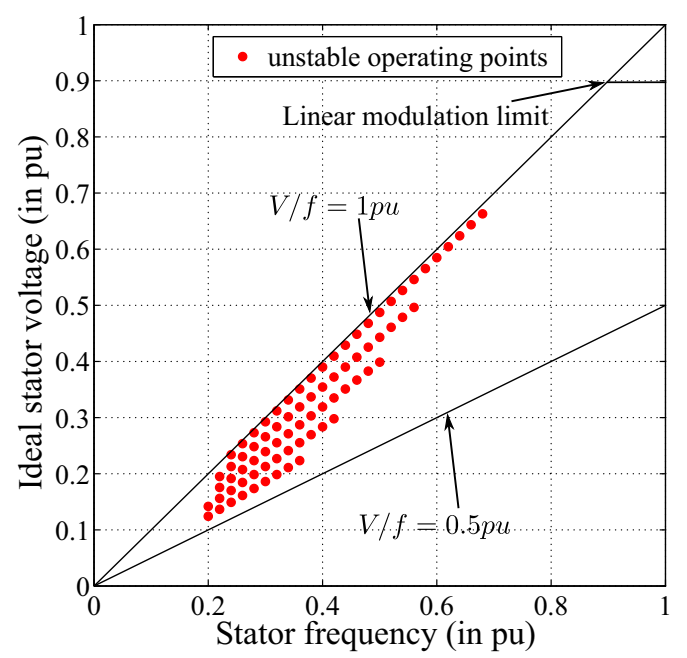

(a)

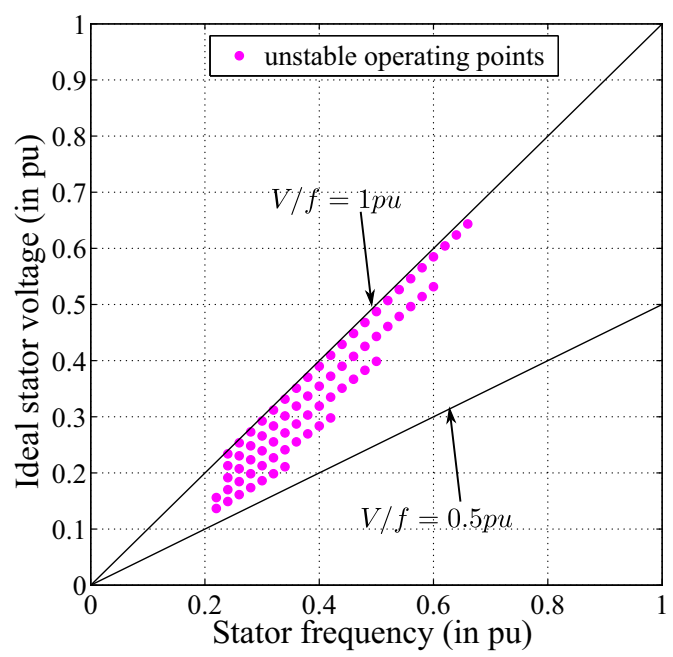

(b)

Figure 9. Experimentally observed set of stable and unstable equilibrium points in the $V-f$ plane for an $11-\mathrm{kW}$ induction motor drive under no load, considering (a) sine-triangle PWM (SPWM) and (b) conventional space vector PWM (CSVPWM). $V_{d c}=600 \mathrm{~V} ; f_{s w}=5 \mathrm{kHz} ; t_{d}=3 \mu \mathrm{s}$.

In the case of the $100-\mathrm{kW}$ induction motor drive, the standard small-signal model is able to predict the subharmonic oscillations, but it is inaccurate in predicting only the region of oscillatory behaviour [9]. However, in case of the present $11-\mathrm{kW}$ motor, the standard smallsignal model is unable to even recognise or indicate possible sub-harmonic oscillations in the drive at certain realistic values of $t_{d} f_{s w}$. Thus, this case study of the $11-\mathrm{kW}$ motor drive better demonstrates the importance of the improved small-signal model in predicting oscillatory behaviour in motor drives.

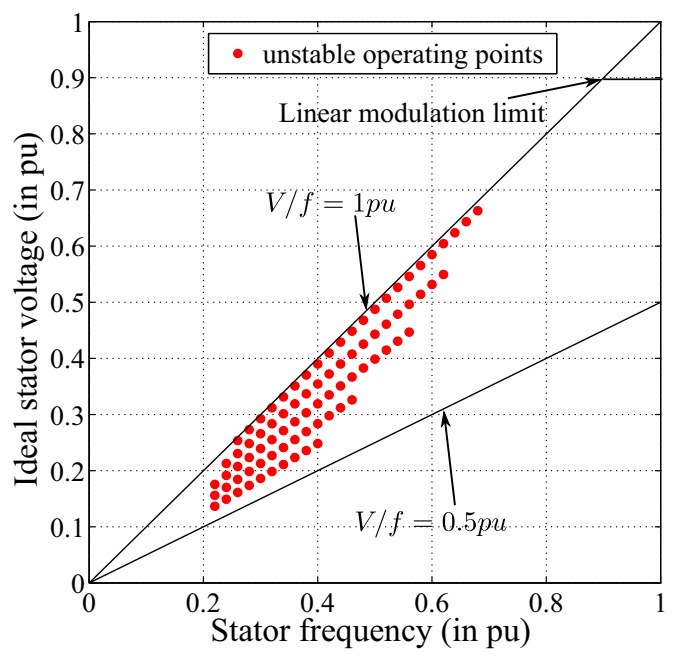

(a)

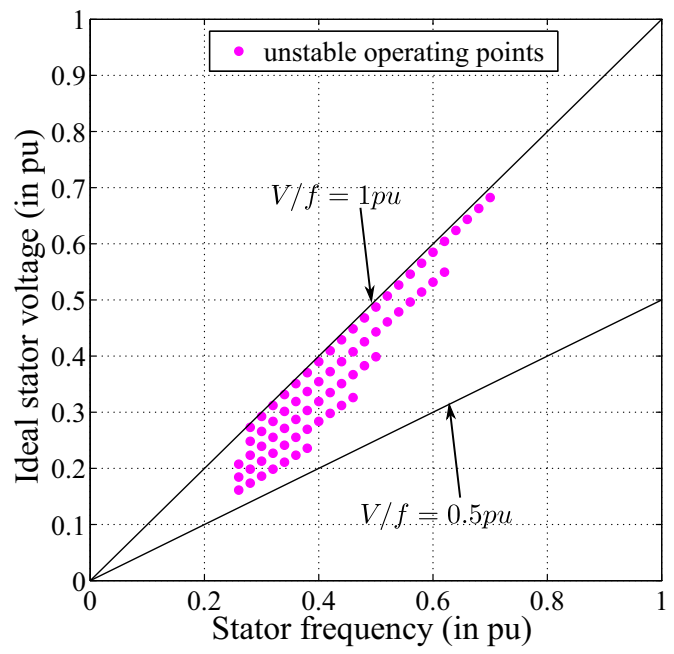

(b)

Figure 10. Experimentally observed set of stable and unstable equilibrium points in the $V-f$ plane for an $11-\mathrm{kW}$ induction motor drive under no load, considering (a) sine-triangle PWM (SPWM) and (b) conventional space vector PWM (CSVPWM). $V_{d c}=600 \mathrm{~V} ; f_{s w}=8 \mathrm{kHz} ; t_{d}=3 \mu \mathrm{s}$.

\section{Conclusion}

This paper investigates whether an 11-kW induction motor drive exhibits oscillatory behaviour and the region of such oscillatory behaviour. The motor drive is found to oscillate in low and medium speeds under no load. The region of oscillatory behaviour increases with the ratio of the deadtime to switching cycle time. The improved small-signal model is shown to be much more accurate than the standard small-signal model in predicting the region of oscillatory behaviour. The regions predicted by the improved model in different cases are confirmed by simulation and 


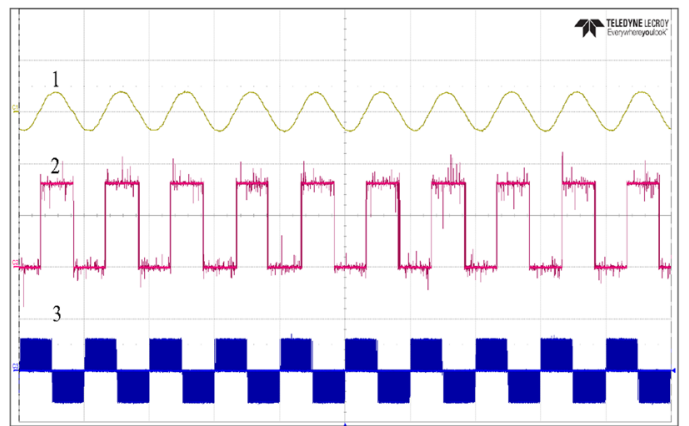

Figure 11. Mitigation of sub-harmonic oscillations with deadtime compensation at a fundamental frequency of $20 \mathrm{~Hz}$ and a $\mathrm{V} / \mathrm{f}$ ratio of $0.89 \mathrm{pu}$ (i.e. operating point $\mathrm{A}$ ). Trace 1: $R$-phase stator current $(20 \mathrm{~A} / \mathrm{div})$, Trace 2: Current polarity detection logic indicative of compensating signal (2V/div) and Trace 3: $v_{R Y}$ line to line voltage (1000 V/div), Time scale: $50 \mathrm{~ms} / \mathrm{div}$.

experimental results. Further, the region of oscillatory behaviour has been shown to be almost the same with sinetriangle and conventional space vector modulation schemes.

Identifying the region of oscillatory behaviour could potentially help in improved design of the motor, or at least, in handling the problem. Dead-time compensation schemes $[7,12,13,18-21]$ and oscillation mitigation schemes $[10,22,23]$ could mitigate these oscillations. Mitigation of these sub-harmonic oscillations using dead-time compensation is also demonstrated in this paper.

\section{Appendix}

The various constituent matrices used in the small-signal model are defined as follows:

$$
\begin{gathered}
\mathbf{L}=\left[\begin{array}{cccc}
L_{s} & 0 & L_{m} & 0 \\
0 & L_{s} & 0 & L_{m} \\
L_{m} & 0 & L_{r}^{\prime} & 0 \\
0 & L_{m} & 0 & L_{r}^{\prime}
\end{array}\right], \\
\lambda_{10}=\left[\begin{array}{c}
0 \\
0 \\
-\left(L_{m} i_{d s 0}+L_{r}^{\prime} i_{d r 0}^{\prime}\right) \\
\left(L_{m} i_{q s 0}+L_{r}^{\prime} i_{q r 0}^{\prime}\right)
\end{array}\right] \lambda_{20}=\left[\begin{array}{c}
L_{m} i_{d r 0}^{\prime} \\
-L_{m} i_{q r 0}^{\prime} \\
-L_{m} i_{d s 0} \\
L_{m} i_{q s 0} .
\end{array}\right] . \\
\mathbf{R}_{r s}=\left[\begin{array}{cc}
0 \\
\mathbf{R}_{s r}=\left[\begin{array}{cc}
0 \\
-\omega_{s 0} L_{m}
\end{array}\right. \\
0 & \left(\omega_{s 0} L_{m}-\omega_{r 0}\right) L_{m} \\
-\left(\omega_{s 0}-\omega_{r 0}\right) L_{m} & 0 \\
r_{r}^{\prime} & \left(\omega_{s 0}-\omega_{r 0}\right) L_{r}^{\prime} \\
-\left(\omega_{s 0}-\omega_{r 0}\right) L_{r}^{\prime} & r_{r}^{\prime} .
\end{array}\right],
\end{gathered}
$$

\section{References}

[1] Nelson R H, Lipo T A and Krause P C 1969 Stability analysis of a symmetrical induction machine. IEEE Trans. Power Apparatus Syst. 88(11): 1710-1717

[2] Fallside F and Wortley A T 1969 Steady-state oscillation and stabilisation of variable-frequency invertor-fed inductionmotor drives. Proc. Inst. Electr. Eng. 116(6): 991-999

[3] Ueda R, Sonoda T, Koga K and Ichikawa M 1992 Stability analysis in induction motor driven by a V/f controlled general-purpose inverter. IEEE Trans. Ind. Appl. 28(2): 472-481

[4] Ueda R, Sonoda T and Takata S 1989 Experimental results and their simplified analysis on instability problems in PWM inverter induction motor drives. IEEE Trans. Ind. Appl. 25(1): 86-95

[5] Colby R S, Simlot A K and Hallouda M A 1990 Simplified model and corrective measures for induction motor instability caused by PWM inverter blanking time. In: Proceedings of IEEE Power Electronics Specialists Conference (PESC), pp. 678-683

[6] Koga K, Ueda R and Sonoda T 1988 Stability problem in induction motor drive system. In: Conference Record of the IEEE Industries Application Society Annual Meeting, pp. 129-136

[7] Guha A, Tripathi A and Narayanan G 2013 Experimental study on dead-time induced oscillations in a $100-\mathrm{kW}$ open-loop induction motor drive. In: Proceedings of National Power Electronics Conference NPEC 2013, IIT Kanpur, pp. 1-6

[8] Guha A and Narayanan G 2014 Small-signal stability analysis of an open-loop induction motor drive including the effect of inverter dead-time. In: Proceedings of IEEE Power Electronics Drives Conference (PEDES), pp. 1-6

[9] Guha A and Narayanan G 2016 Small-signal stability analysis of an open-loop induction motor drive including the effect of inverter dead-time. IEEE Trans. Ind Appl. 52(1): 242-253

[10] Guha A and Narayanan G 2015 Inductance-emulation-based active damping of dead-time-induced oscillations in a $100-\mathrm{kW}$ induction motor drive. In: Proceedings of IEEE ITEC-India, pp. 1-6

[11] Krishnan R 2001 Electric motor drives-modelling, analysis and control. Prentice Hall Inc., Upper Saddle River, New Jersey

[12] Murai Y, Watanabe T and Iwasaki H 1987 Waveform distortion and correction circuit for pwm inverters with switching lag-times. IEEE Trans. Ind. Appl. (5): 881-886

[13] Jeong S G and Park M H 1991 The analysis and compensation of dead-time effects in PWM inverters. IEEE Trans. Ind. Electron. 38(2): 108-114

[14] Guha A and Narayanan G 2016 Modelling and analysis of induction motor drive including the effect of inverter deadtime. Sadhana 41(2): 125-145

[15] Ahmed S, Shen Z, Mattavelli P, Boroyevich D, Jaksic M, Karimi K and Fu J 2011 Small-signal model of a voltage source inverter (VSI) considering the dead-time effect and space vector modulation types. In: Proceedings of IEEE Applied Power Electronics Conference and Exposition (APEC) pp. 685-690

[16] Guha A and Narayanan G 2013 Average modelling of a voltage source inverter with dead-time in a synchronous 
reference frame. In: Proceedings of IEEE Innovative Smart Grid Technologies-Asia (ISGT Asia), pp. 1-6

[17] Guha A, Chetty A, Kumaresan C, Narayanan G and Krishnamoorthy R 2015 Theoretical prediction and experimental verification of light-load instability in a $11-\mathrm{kW}$ open-loop induction motor drive. In: Proceedings of National Power Electronics Conference NPEC 2015, IIT Bombay, pp. 1-6

[18] Leggate D and Kerkman R J 1997 Pulse-based dead-time compensator for PWM voltage inverters. IEEE Trans. Ind. Electron. 44(2): 191-197

[19] Park D M and Kim K H 2014 Parameter-independent online compensation scheme for dead time and inverter nonlinearity in IPMSM drive through waveform analysis. IEEE Trans. Ind. Electron. 61(2): 701-707
[20] Zhang Z and Xu L 2014 Dead-time compensation of inverters considering snubber and parasitic capacitance. IEEE Trans. Power Electron. 29(6): 3179-3187

[21] Mannen T and Fujita H 2015 Dead time compensation method based on current ripple estimation. IEEE Trans. Power Electron. 30(7): 4016-4024

[22] Lee K, Yao W, Chen B, Lu Z, Yu A and Li D 2014 Stability analysis and mitigation of oscillation in an induction machine. IEEE Trans. Ind. Appl. 50(6): 3767-3776

[23] Chen B, Yao W, Lu Z and Lee K 2014 A novel stator flux oriented V/f control method in sensorless induction motor drives for accuracy improvement and oscillation suppression. In: Proceedings of IEEE Energy Conversion Congress and Exposition (ECCE), pp. 5092-5099 